\title{
As três margens do rio e o vertiginoso fluxo da vida
}

\author{
ANDRÉ LUIS RODRIGUES I
}

\author{
"Todos os rios do mundo de Guimarães Rosa têm três margens." \\ (Paulo Rónai, “Os vastos espaços”) \\ “Às vezes Guimarães Rosa escreve como quem está em estado de graça; \\ 'A terceira margem do rio' é um desses casos." \\ (Walnice Nogueira Galvão, "Do lado de cá”, Minima mímica)
}

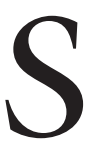

E UM DOS meios mais eficazes de se avaliar a qualidade de uma obra literária é de fato o teste da releitura, "A terceira margem do rio" é inegavelmente uma obra-prima. Cada nova leitura parece tão impactante quanto a primeira. Lida a última linha, uma mistura de forte emoção e grande perplexidade toma conta do leitor, o que tende a se repetir nas leituras seguintes.

O mistério que envolve o conto, narrado em primeira pessoa, não impede que seu enredo seja relativamente simples. Um pai de família toma a inusitada decisão de passar a viver dentro de uma canoa no rio que corre ao lado de sua fazenda. A mãe se opõe e um dos três filhos pequenos, aquele que depois vai contar a história, se oferece para ir junto, mas o pai não o leva. A família e as pessoas do lugar se perguntam sobre os possíveis motivos de procedimento tão espantoso e incompreensível. Imaginam todos que o pai logo irá se arrepender, mas a falta de êxito se repete nas tentativas de fazer que ele volte para casa. Ainda que não desapareça de todo, ele não tem mais contato com os familiares. Sua sobrevivência parece garantida por aquele filho, que, com a ajuda velada da mãe, deixa mantimentos perto da margem do rio. Os anos passam, a irmã se casa e tem um filho, o irmão muda-se para a cidade, e finalmente a mãe vai viver com a irmã. Só o narrador envelhece à margem do rio, e um dia resolve chamar o pai e oferecer-se para ocupar o lugar dele na canoa. O pai surge e parece aceitar a oferta, começando a remar ao encontro do filho. Este, porém, sente um medo incontrolável e foge. No fim do conto, expõe as suas dúvidas sobre as próprias ações, a decepção com o seu fracasso e o seu sentimento de culpa.

As primeiras reflexões sobre essa narrativa enigmática, em que não há qualquer referência mais precisa ao tempo e ao lugar em que ocorrem os fatos (o próprio nome do rio nunca é mencionado), podem começar talvez pelo título, especialmente por ser tão singular e intrigante quanto a própria história. Sabemos que todo rio tem duas margens, a esquerda e a direita, mas quem 
imaginaria defrontar-se - antes, claro, de tomar conhecimento do conto - com a alusão a uma terceira margem? A notável expressão de Rosa parece resultado de dois procedimentos básicos: a aproximação e a distinção. Pelo primeiro, ao atribuir o nome de margem ao leito do rio, são sugeridas as semelhanças que ele tem com suas margens. Pelo segundo, ao qualificar essa outra "margem" de "terceira" e ao elegê-la como título do conto, determinando-a pelo artigo definido e, assim, desvinculando-a das "outras" margens, o escritor insinua ser ela diferente, distinta delas.

Semelhanças entre o que é essencialmente diferente permitem pensar em intersecções, os lugares onde surgem as coincidências, que é o que se dá com a figura da metáfora. As águas do rio invadem as margens nas cheias, e as margens "avançam" sobre as águas em eventuais desbarrancamentos. Esses podem formar ilhas e croas (bancos de areia) no leito do rio, que são por assim dizer a presença das margens no centro do fluxo de suas águas. Mas o desbarrancamento é também um modo de esse fluxo ocupar um espaço que originalmente pertencia a uma das margens. Os brejos que ocorrem perto das margens são também "mistura" de água e terra, isto é, leito e margem. A vegetação (juncos e mato) que costuma recobri-los estende-se eventualmente até as margens, tornando indistintos os limites entre a terceira e as duas outras margens do rio.

Mais evidentes parecem ser as diferenças: terra de um lado e água de outro; sólido e líquido; imobilidade e fluidez; firmeza e inconsistência; estabilidade e instabilidade; segurança e insegurança; superficialidade e profundidade; estreiteza e largueza ou vastidão - "o rio por aí se estendendo grande, fundo, calado que sempre. Largo, de não se poder ver a forma da outra beira". ${ }^{1}$

Nada substitui a experiência para atribuir, imediatamente e sem qualquer equívoco, características como estabilidade, firmeza e segurança ao solo por oposição ao movimento instável das águas. Aqueles que já passaram mal no interior de um barco, talvez uma das piores sensações que o homem - criatura terrestre por excelência - pode experimentar (composta de enjoo, náusea, vômito, mal-estar, dor de cabeça, vertigem, fraqueza...), sabem como é praticamente instantânea a cessação desses males (que pareciam antes intermináveis, assim como a vastidão das águas parecia infinita e a margem, inatingível) e súbita a melhora tão logo consegue colocar os dois pés em terra firme. O "milagre" que então parece produzir-se não encontra qualquer correspondente nos paliativos que tentam gradativamente e a custo minimizar os sintomas produzidos no corpo humano pelo movimento oscilante das águas. A expressão terra firme, por sinal, de certo modo tautológica, é indício desse aspecto benfazejo da terra, então qualificada de firme, àqueles que se encontram num barco ou navio, pois ela não se opõe a qualquer terra que não seja firme - lamaçal, brejo, areia movediça -, mas à água, movente, fluida, instável, inconsistente, insegura.

Num outro nível de significação, o movimento das águas do rio alude ao que é mais vivo, ativo, pulsante. Não por acaso, conota também a passagem do 
tempo, o envelhecimento, que é próprio do que vive, ainda que seja prenúncio da morte. O estático das margens, por sua vez, pode ser associado ao esforço sobre-humano para estabilizar, fixar, imobilizar tudo o que é por natureza instável, livre, móvel, isto é, o esforço que o homem vem fazendo desde tempos imemoriais para tornar-se civilizado. Àqueles pares de opostos que advêm tão logo imaginamos um rio concreto podem ser então acrescentados outros, advindos de crescentes níveis de mediação: conhecido e desconhecido; constrangimento e liberdade; ordem e desordem; sedentarismo e nomadismo; domesticado e selvagem; civilizado e "primitivo"; sociedade e natureza. Civilização é resultado, entre outras coisas, da busca por segurança (evitar os perigos) e perpetuação (lutar contra a morte). Toda a energia que parece ter sido aplicada para tornar a vida mais segura e conter a passagem do tempo, que leva à morte, acaba atuando também e paradoxalmente no sentido de negação da vida, com a supressão do que lhe é mais característico, o movimento e a transformação.

O jovem Sérgio Buarque de Holanda, num belíssimo ensaio que deu origem, na segunda metade dos anos de 1920, a um dos mais fecundos debates intelectuais de nossa história, com Tristão de Athayde, intitulado "Perspectivas", já associava as primeiras manifestações artísticas miméticas, contemporâneas das incipientes formas de organização social entre os homens, à tentativa de interromper o curso livre da vida:

Parece claro que o próprio impulso que levou os primeiros homens a gravar desenhos nas paredes das cavernas participa muito, não de um desejo de libertação como já se tem dito (isto é, libertação no sentido de exaltação, correspondendo a uma expansão de vitalidade), não de esforço de resistência contra o aniquilamento, mas ao contrário, e acentuadamente, ao desejo invencível de negar a vida em todas as suas manifestações. (Holanda, 1996, p.217, grifo do autor)

Expressões como "perder o chão" ou "o chão desapareceu sob seus pés", e ainda o que é quase o oposto disso, o adjetivo "chão" empregado com o sentido de habitual, comum ou trivial, apontam para a sensatez, o preparo e o controle de si daquele que se acostumou a ter os pés plantados ou fincados no solo, que há muito trocou o nomadismo pelo sedentarismo, o uso comunitário da terra pela propriedade privada, o mundo natural pelos artefatos e artifícios da civilização. Ocorre que mesmo para o mais civilizado dos homens, ainda aquele que melhor pode desfrutar dos confortos propiciados por uma civilização que atingiu um nível de desenvolvimento verdadeiramente notável, a sedução do retorno à natureza e à vida mais plenamente vivida está sempre presente, ainda que de modo latente. A repressão às pulsões traz com ela o risco de violento e incontrolável regressão, na medida mesma da violência com que foi bloqueado o livre curso das satisfações pulsionais - para falarmos com Freud, o reprimido sempre retorna. As margens que constrangem o curso do rio constituem uma bela imagem dos desejos humanos constrangidos pela vida em sociedade: as cheias e o rompimento do curso normal, com o transbordamento violento das águas por sobre as margens, é sempre uma possibilidade. 
Não é bem isso, contudo, o que ocorre no conto de Guimarães Rosa. E já não é sem tempo que voltemos a ele. A decisão - tomada com consciência e ponderação por aquele que "era homem cumpridor, ordeiro, positivo" (aquele que cumpre suas obrigações; que pratica a ordem e tem bom comportamento; que é útil, prático, construtivo ${ }^{2}$ - de abandonar a família e lançar-se nas águas do rio, não como travessia, passagem de uma margem a outra, mas permanência nessa terceira margem é, desde que o homem radicon-se em uma das duas margens, o evento inaudito: "Aquilo que não havia, acontecia", na formulação paradoxal e particularmente inventiva do escritor. De tão extraordinária, a ação só pode ser da ordem do evento - mágico, maravilhoso - e não da existência comum. O emprego dos dois verbos no imperfeito, de aspecto durativo, quando esperaríamos o segundo verbo no pretérito perfeito, parece desmentir a existência do acontecimento mesmo que está sendo narrado, isto é, acontece, mas é como se continuasse a não existir.

A escolha do pai é pelo mergulho no centro da vida (sorvedouro, turbilhão, voragem $),{ }^{3}$ com sua turbulência, seus perigos e riscos, e um mais próximo convívio com a morte - "E a constante força dos braços, para ter tento na canoa, resistido, mesmo na demasia das enchentes, no subimento, aí quando no lanço da correnteza enorme do rio tudo rola o perigoso, aqueles corpos de bichos mortos e paus-de-árvore descendo - de espanto de esbarro". ${ }^{4}$ Para a sociedade, contudo, uma tal escolha é inaceitável, incompreensível e motivo de vergonha para a família, pois implica a recusa dos valores basilares e das primeiras conquistas fundamentais da civilização, o domínio do fogo e o emprego da linguagem "Mas não armava um fogninho em praia, nem dispunha de sua luz feita, nunca mais riscou um fósforo. [...] E nunca falou mais palavra, com pessoa alguma". A família - unidade fundamental para a existência da sociedade e a defesa de seus valores - paga por assim dizer na mesma moeda: "Nós, também, não falávamos mais nele". Mas essas recusas do pai são precedidas pela primeira e determinante recusa de qualquer convívio humano, ainda que não implicasse o distanciamento total e definitivo da família, a opção pela vida solitária vivida no leito do rio: "Encomendou a canoa especial, de pau de vinhático, pequena, mal com a tabuinha de popa, como para caber justo o remador"; "nosso pai nunca se surgia a tomar terra, em ponto nem canto, de dia nem de noite, da forma como cursava no rio, solto solitariamente".

Já a maior proximidade da natureza conduz ao distanciamento da civilização - "Mas eu sabia que ele agora virara cabeludo, barbudo, de unhas grandes, mal e magro, ficado preto de sol e dos pelos, com o aspecto de bicho, conforme quase nu..." -, que é representada em primeiro lugar pela família. Ainda que esta, em "A terceira margem do rio", viva no campo, num momento que parece muito distante ainda da mais ou menos recente modernização que vem ocorrendo em algumas regiões do país, os índices apontam todos para uma cultura em estágio relativamente "avançado" e mesmo em movimento na direção de 
maior adiantamento: o tio que é chamado para "auxiliar na fazenda e nos negócios" (a agricultura sedentária e o comércio); o mestre que chega para ensinar os meninos (a educação mais ou menos formal); o padre que também é chamado para ordenar ao pai que desistisse de sua "tristonha teima" (a religião católica); os soldados que vêm para tentar amedrontá-lo (a polícia) e os homens do jornal que, sem sucesso, vêm para fotografá-lo (a imprensa); o casamento da irmã, vestida de branco (a união matrimonial); o irmão que vai para a cidade (a urbanização); a própria casa que será depois sintomaticamente deslocada para mais longe do rio - "Nossa casa, no tempo, ainda era mais próxima do rio, obra de nem quarto de légua...".

A primeira desconfiança da mãe é de que o pai, "que nessas artes não vadiava", iria se voltar "para pescarias e caçadas", mal desconfiando de que o retorno empreendido por ele seria para um tempo ainda mais remoto do que aquele do homem caçador-coletor. O emprego do verbo vadiar evidentemente não é casual. Rosa, mestre insuperável na expressão linguística e na escolha vocabular, sugere a verdade que se oculta no emprego pejorativo da palavra vadiar por quem vê o trabalho como o valor mais alto da sociedade e o lazer, ou o ócio, como o maior dos pecados. O que o pai decidira era exatamente viver a "perambular", a "vagar sem rumo, ao acaso", que é o sentido original desse verbo. A direção das ações paternas parece apontar para o sentido oposto àquela que vai sendo tomada pela família, para o que há de mais arcaico, na medida mesma em que ela ruma para o mais moderno.

O caráter tão inusitado e inexplicável do fato faz que as pessoas se vejam diante da necessidade de buscar explicações que se conformem ao esperado, ao compreensível, ao já acontecido e conhecido. A primeira explicação, a mais óbvia e, por isso, generalizada: a loucura - “todos pensaram de nosso pai a razão em que não queriam falar - doideira”. Na frase tão significativa, a loucura seria ainda uma razão (a causa, o motivo) para o que parece de todo irracional. Depois, uns poucos ("Só uns") aventam outros possíveis motivos: uma promessa ou "alguma feia doença” (a lepra), que o tivesse levado a manter-se longe da família, sem abandoná-la de todo ("se desertava para outra sina de existir, perto e longe de sua família dele”). A dúvida, porém, permanece e, mais à frente, quando surgem as primeiras cheias do rio e sem sinal de estiagem, alguns imaginam que o pai teria sido avisado, como Noé, da chegada de um novo dilúvio e por isso teria feito a canoa. Mas isso eram, segundo o filho, "as falsas conversas, sem senso". Até a explicação mais insensata é buscada para tentar compreender o absolutamente incompreensível.

A suposição de que o pai não tinha afeição pela própria família também não é capaz de atribuir sentido ao que a todos parece inteiramente sem sentido e além de toda compreensão: "Nem queria saber de nós; não tinha afeto? [...] se ele não se lembrava mais, nem queria saber da gente, por que, então, não subia ou descia o rio, para outras paragens, longe, no não-encontrável? Só ele soubesse”. Desco- 
brir que não eram amados pelo patriarca seria um duro golpe para os membros da família, mas ao menos os tiraria da terrível dúvida em que não conseguem deixar de se enredar. Nem isso lhes era dado, pois a proximidade do pai podia ser indício de que não desejava cortar todos os laços que o ligavam à família.

Assim, o mistério permanecerá irredutível: a explicação existe, foi dada pelo pai, mas não há mais como chegar a ela, com a morte de seu depositário: "quando eu quis mesmo saber, e firme indaguei, me diz-que-disseram: que constava que nosso pai, alguma vez, tivesse revelado a explicação, ao homem que para ele aprontara a canoa. Mas, agora, esse homem já tinha morrido, ninguém soubesse, fizesse recordação, de nada mais". Extraordinária imagem dos limites do conhecimento humano e da impotência a que muitas vezes o homem não tem como não se resignar.

Não será esse o único mistério: a história toda se desenvolve sob o signo do misterioso, da perplexidade e da ambiguidade, que passa inclusive por esse "quando eu quis mesmo saber". Antes não o quisera? Não sabia se realmente o queria? Será que é porque desconfiava que a verdade, se passível mesmo de ser alcançada, poderia causar tão grande espanto e medo que seria preferível não conhecê-la? E assim incertas e ambíguas parecem ser as atitudes de todos, a começar pela mãe, que, depois de categoricamente intimar o pai a que, se fosse, nunca mais voltasse - "Cề vai, ocế fique, você nunca volte!”-, não só faz vistas grossas ao fato de que o filho leva "escondido" mantimentos ao pai, como chega a facilitar a tarefa que ele tomara para si. Na notável frase da mãe, expresso no emprego do imperativo, reiterado no imperativo negativo intensificado pelo advérbio nunca (em nenhum tempo, jamais, em nenhuma circunstância), com os verbos estritamente conjugados de acordo com a norma culta, e ainda na progressiva passagem do mais informal para o menos - "Cê", "ocê" e "você" -, que parece materializar no enunciado o gradativo, mas cabal, distanciamento do interlocutor, ${ }^{5} \mathrm{O}$ definitivo dessa ordem é assim relativizado pela preocupação posterior com o destino do pai e pelas próprias ações para ajudar o filho a alimentá-lo, que ela procura esconder, sem contar ainda as tentativas para, valendo-se do padre e dos soldados, trazer o marido de volta.

Mais do que essas atitudes da mãe, causará surpresa a do próprio narrador ao final do conto. Antes, porém, de narrar esse evento crucial e espantoso, o que ele nos revela é a inapelável passagem do tempo. Instalado na relativa segurança de uma das duas margens ou vagando pela terceira, o tempo passa para todos, pois dele não há como escapar. Pai e filho envelhecem igualmente: "Eu sofria já o começo de velhice - esta vida era só o demoramento. Eu mesmo tinha achaques, ânsias, cá de baixo, cansaços, perrenguice de reumatismo. E ele? Por quê? Devia de padecer demais. De tão idoso, não ia, mais dia menos dia, fraquejar do vigor..." É o mesmo inevitável destino que espera os que mergulham na vida sem fazer caso da morte, e os que de algum modo a antecipam acreditando poder conjurá-la. 
A partir daí o filho dá início à narração do episódio final, introduzido, não por acaso, pelo questionamento sobre a própria loucura: "Sou doido? Não. Na nossa casa, a palavra doido não se falava, nunca mais se falou, os anos todos, não se condenava ninguém de doido. Ninguém é doido. Ou, então, todos" (grifo do escritor). Quando finalmente se decide a chamar o pai, sem qualquer esperança de que ele acudisse ao chamado, para propor tomar o lugar dele na canoa e no rio, e quando, contrariando igualmente todas as expectativas, o pai parece aceitar ser substituído pelo filho, este recua apavorado e foge do destino a que ele mesmo estava prestes a se impor. Mas por que a culpa, por que tão insistente pedido de perdão? E a quem? Ao pai? Ao interlocutor, isto é, a nós, leitores? A si mesmo? Por que o questionamento da própria humanidade ou de sua masculinidade? Por que o pedido final?

Como no relato de Heródoto citado por Benjamin, no célebre ensaio "O narrador", várias interpretações para esse final surpreendente podem ser propostas, todas provavelmente válidas: é da ordem das coisas que o filho substitua o pai e, não o fazendo, só há lugar para o sentimento de culpa e o remorso; o filho acredita ter sido escolhido pelo pai para dar continuidade ao seu projeto, mas sente que não está à altura dessa eleição, e é dessa limitação que advém o sentimento de culpa; o filho costuma ser diferente do pai ou, na afirmação de sua individualidade, faz questão de o ser, e a continuidade entre as gerações está assim quase sempre fadada ao fracasso; o drama do filho reside no impasse gerado pela dúvida indecidível entre seguir o próprio caminho e aquele trilhado pelo pai, entre voltar-se para o passado, como ele, e seguir em direção ao futuro, como os outros membros da família; a inesperada aceitação por parte do pai de ser substituído pelo filho faz com este vislumbre apavorado as reais dificuldades da empresa e acabe desistindo dela, o que o cobre de vergonha e de culpa; a perspectiva da substituição leva o filho a perceber num relance que, não tendo filhos, não teria quem viesse um dia a substituí-lo, por isso é dominado pelo pavor e depois pelo arrependimento; o pai é mesmo uma assombração vista pelo filho ou uma projeção de seus desejos irrealizados, e assim a fuga do fantasma nada mais é que uma fuga de si mesmo.

A interpretação mais coerente com a leitura que venho fazendo seria pensar as frases finais do narrador no contexto do arrependimento por não ter conseguido rejeitar, nem mesmo na velhice, a segurança dos "rasos do mundo" para, na esteira do exemplo paterno, se lançar nas profundezas turbilhonantes e vertiginosas da vida, correndo todos os riscos advindos dessa escolha. Contudo, parece que essa como quaisquer outras interpretações não faz (felizmente?) cessar o mistério que se desprende do final do conto a cada nova leitura:

Sofri o grave frio dos medos, adoeci. Sei que ninguém soube mais dele. Sou homem, depois desse falimento? Sou o que não foi. ${ }^{6}$ o que vai ficar calado. Sei que agora é tarde, e temo abreviar com a vida, nos rasos do mundo. Mas, então, ao menos, que, no artigo da morte, peguem em mim, e me depositem também numa canoinha de nada, nessa água que não para, de longas beiras: e, eu, rio abaixo, rio a fora, rio a dentro $-\mathrm{o}$ rio. 
Esse mistério que cerca as coisas, essa impossibilidade de discernimento, de descoberta dos móveis das ações mais surpreendentes e inesperadas, mesmo e sobretudo em relação às próprias ações, pode remeter a um outro nível de significação para essa inquietante terceira margem. Para tentar melhor compreendê-lo, pode-se lançar mão de dois textos verdadeiramente instigantes: o primeiro, um ensaio fundamental sobre a duração e a flecha do tempo, escrito pelo sociólogo americano Immanuel Wallerstein (2003), intitulado "O tempo, a duração e o terceiro não excluído"; o segundo, um fragmento da Dialética do esclarecimento, de Max Horkheimer e Theodor Adorno (1985).

Em seu ensaio, Wallerstein discute a obra de duas figuras de destaque no século XX, cujas reflexões tornaram-se fundamentais em suas respectivas áreas de conhecimento e mesmo para além delas: o historiador Fernand Braudel e o físico-químico Ilya Prigogine. A importância do trabalho e do pensamento de Braudel estaria ligada sobretudo à proposição da noção ou do conceito de longa duração, por oposição, de um lado, à história dos eventos, que tudo vê em escala minúscula, preocupada apenas com o "infinitamente pequeno" - a "curta duração" -, e de outro aos modelos nomotéticos, isto é, baseados em leis gerais e universais - a "longuíssima duração". A longa duração estaria ligada ao conceito de estrutura, assim definido por Braudel: "articulação, arquitetura, porém mais ainda uma realidade que o tempo mal desgasta e transporta muito longamente. Todas [as estruturas] são ao mesmo tempo sustentáculos e obstáculos" (apud Wallerstein, 2003, p.74). Contudo, Braudel não estaria propondo a recusa dos eventos, mas a existência de "tempos sociais múltiplos", no que poderia ser descrito como uma "dialética das durações", ou no que Wallerstein, denomina "o terceiro não excluído": "simultaneamente tempo e duração, um particular e um universal, que são simultaneamente os dois termos e nenhum deles" (ibidem, p.75).

Já a importância do trabalho de Prigogine e de seus "estudos da complexidade" estaria ligada fundamentalmente à reintrodução do conceito de tempo, mais propriamente a flecha do tempo, no campo da física e das ciências da natureza em geral. Desconsiderada pela mecânica e pela dinâmica newtoniana, a irreversibilidade dos fenômenos que acompanhamos em praticamente tudo o que cerca nossa vida é o centro do trabalho desenvolvido por ele, especialmente a partir dos anos 1970. Ao contrário de Braudel, que teve de lutar pelo reconhecimento da longa duração num meio que se preocupava apenas com os eventos, isto é, com o tempo, Prigogine precisou dar destaque à irreversibilidade dos fenômenos, isto é, ao tempo, uma vez que a duração (ainda que um tipo bem específico de duração) era já levada em consideração pela física clássica. De todo modo, o mesmo que foi dito de Braudel pode ser repetido com respeito a Prigogine: a permanência no terreno do terceiro não excluído - tempo $e$ duração. A expressão "caos determinista" dá muito bem a noção desse modo complexo de ver as coisas: a recusa em aceitar o determinismo como explicação de todos os fenômenos não significa acreditar que tudo seja inteiramente caótico. Con- 
siderar que as certezas dão lugar agora às incertezas não significa acreditar que o conhecimento perfeito e indiscutível seja substituído pelo desconhecimento geral e irrestrito, mas apenas que a realidade torna-se mais difícil de conhecer e que esse conhecimento estará sempre no campo do provável, do aproximado, do instável, do imperfeito, do interminável.

O primeiro e mais óbvio ponto de contato entre o conto de Rosa e os estudos de Braudel e Prigogine, como considerados por Wallerstein, é a questão do tempo - "Os tempos mudavam - no devagar depressa dos tempos". O oxímoro "devagar depressa" parece aludir exatamente ao caráter multifacetado da passagem do tempo. Aliás, pensando no que há de paradoxal nessa expressão, podemos nos lembrar da famosa entrevista concedida a Günter Lorenz, em que Rosa afirma: "Os paradoxos existem para que ainda se possa exprimir algo para o qual não existem palavras" (apud Coutinho, 1983, p.68). Mais impressionante é talvez o modo como o escritor logra fazer a linguagem sugerir a gradativa aceleração de acontecimentos que, mesmo sendo apenas imaginados, acabam por se precipitar na mesma velocidade crescente do movimento tumultuoso das águas: "De tão idoso, não ia, mais dia menos dia, fraquejar do vigor, deixar que a canoa emborcasse, ou que bubuiasse sem pulso, na levada do rio, para se despenhar horas abaixo, em tororoma e no tombo da cachoeira, brava, com o fervimento e morte".

Para além da questão do tempo, talvez não seja despropositado, na leitura do conto de Rosa, estender o conceito de "terceiro não excluído", proposto por Wallerstein, para todas as situações em que somos constrangidos a optar entre uma e apenas uma coisa e outra, o que é próprio do pensamento binário. ${ }^{7} \mathrm{Em}$ tudo o que se nos apresenta como um par de opostos que reciprocamente se excluem, isto é, em que um elemento tem de ser escolhido como o certo ou o verdadeiro, sendo o outro necessariamente errado ou falso, vedada a consideração de um terceiro elemento - tertius non datur-, deveríamos, ao contrário, pensar numa terceira possibilidade, que não negaria um e outro dos elementos contraditórios, mas que participaria de ambos. Para ilustrar a dificuldade desse pensamento mais complexo, pode-se agora recorrer a Adorno e Horkheimer. Num fragmento do clássico Dialética do esclarecimento, intitulado "Contradições", os teóricos alemães encenam um diálogo entre dois jovens - A e B - para ilustrar a exigência que sempre se faz de "fornecer um princípio universal": "A doutrina só precisa ser geral, segura de si, universal e imperativa. O que é intolerável é a tentativa de escapar à disjuntiva 'ou isso - ou aquilo', a desconfiança do princípio abstrato, a firmeza sem doutrina” (Horkheimer; Adorno, 1985, p.222). A esse diálogo, em que o interlocutor A tenta de todos os modos obter uma posição fixa e inequívoca de $\mathrm{B}$, que tem um pensamento aberto, acusando-o sempre de que ele se contradiz, segue-se a conclusão do fragmento:

Esse diálogo se repete sempre que uma pessoa não quer abrir mão do pensamento em benefício da prática. Ela vai sempre encontrar a lógica e a coerência no lado contrário. Quem for contra a vivissecção não deve fazer nenhum movi- 
mento respiratório, porque isto pode custar a vida a um bacilo. A lógica está a serviço do progresso e da reação, ou, em todo caso, da realidade. Mas, na época de uma educação radicalmente realista, os diálogos tornaram-se mais raros, e o interlocutor neurótico B precisa de uma força sobre-humana para não ficar são.

(ibidem, p.223-4)

Gostaria de chamar a atenção apenas para o paradoxo da inversão final. Em tempos de sinais trocados, só se pode encontrar lucidez na insanidade, o que pode ser aproximado talvez do paradoxo do Sérgio Buarque de "Perspectivas" "Só à noite enxergamos claro" - e daquele de Rosa em "A terceira margem do rio" - "o que não era o certo, exato; mas que era mentira por verdade".

Podemos agora voltar às oposições feitas inicialmente e revê-las com outros olhos, buscando escapar à lógica que nos é comumente imposta, da doutrina geral, universal e imperativa, na tentativa de encontrar uma outra razão, uma "racionalidade radical", talvez, para falar com Luiz Costa Lima (1983, p.508): em lugar de "imobilidade" ou "fluidez", imobilidade $e$ fluidez; estabilidade $e$ instabilidade; constrangimento $e$ liberdade; ordem $e$ desordem; civilizado $e$ "primitivo". Em outras palavras, o terceiro não excluído, a terceira margem do rio, ${ }^{8}$ com suas ilhas, croas e brejos, mas também com a margem da direita e a da esquerda. Afinal, não existe rio sem margens, o que pode, é claro, ser observado diretamente na natureza, mas que também se evidencia na bela imagem constituída pelo ideograma japonês correspondente à palavra "rio" (kawa):9

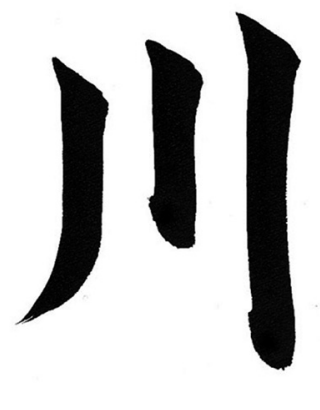

kawa

Se a opção paterna pela terceira margem pode ser vista como tresloucada, é somente na medida em que ele parece recusar quase tudo o que pertenceria às outras duas margens. Mas seria menos absurda a pretensão de recusar inteiramente a terceira?

Nosso pai não voltou. Ele não tinha ido a nenhuma parte. Só executava a invenção de permanecer naqueles espaços do rio...

A invenção é o que é mais próprio da arte e da literatura, e talvez não seja descabido pensar a própria literatura a partir do conto. Se aceitarmos a definição poundiana de literatura como linguagem carregada de sentido no mais alto grau, a medida de sua grandeza deve ser determinada especialmente pelo modo 
como ela escapa à lógica tradicional e busca uma outra lógica, que contemple não uma ou outra perspectiva de ver o mundo, geralmente excludentes, mas para me valer uma vez mais de Luiz Costa Lima (1983, p.503) - de um "leque de perspectivas", todas igualmente válidas. Na esteira desse reconhecimento, a interpretação, por sua vez, deve sempre levar em conta algumas dessas perspectivas ou possibilidades, considerando que outras virão a ser desveladas, sendo o processo hermenêutico tão interminável como o são as outras formas de conhecimento humano.

O ensaio de Wallerstein começa com a relativização da separação entre as ciências da natureza e a filosofia, as artes e as letras, determinando-a historicamente, e termina com uma citação de Alfred North Whitehead, que fala da ciência, mas que, com pequenas modificações, poderia falar antes da literatura e das artes, não apenas do século XX, mas de todos os tempos:

A ciência moderna impôs à humanidade a necessidade de vadiagem. Seu pensamento e sua tecnologia progressivos fazem da transição através do tempo, de uma geração a outra, uma verdadeira migração em meio a oceanos inexplorados de aventuras. O interesse da vadiagem está em que ela é perigosa e por isso necessita de habilidade, a fim de evitar os maus impasses. Devemos, pois, esperar que o futuro nos revele perigos. É próprio do futuro ser perigoso; e um dos méritos da ciência é equipar o futuro para fazer frente a seus deveres. (apud Wallerstein, 2003, p.79)

Assim como a vida, e talvez tão complexa quanto ela, sobretudo no caso de obras como a de Guimarães Rosa, a literatura (aliás, não poderia ela ser definida, entre outras coisas, como vadiagem em meio a oceanos inexplorados de aventuras?) parece valer mais a pena na medida da disposição em correr riscos, mas a habilidade humana está aí para enfrentar os desafios e tentar superá-los. Entre a inovação e a tradição, entre o moderno e o arcaico, entre o tempo e a duração, entre o arrojo e a contenção, há sempre um caminho que participa de ambos os lados e que segue entre eles, ora sinuoso, ora mais linear, ora veloz, ora mais lento, ora avançando para a margem da direita, ora para a da esquerda, mas sempre largo, caudaloso, profundo: “- o rio".

\section{Notas}

1 Todas as citações do conto feitas ao longo do ensaio foram extraídas da $26^{\text {a }}$ edição da Nova Fronteira de 1993. Considerando a curta extensão do conto, optei por não mencionar os números de página para evitar sobrecarregar o texto. Exceto numa única ocorrência, explicitada imediatamente depois da citação, e nos casos de discurso direto, cujos caracteres são realçados por Rosa juntamente com o emprego do travessão, o itálico indica grifo meu.

2 Sem a pretensão de estabelecer qualquer relação mais direta com a descrição do caráter paterno, pode-se notar como ela se aproxima do lema comtiano do positivismo: “O amor por princípio e a ordem por base; o progresso por meta". 
3 É o que Luiz Costa Lima (1983, p.508) já havia constatado no agudo ensaio que escreveu pouco depois da publicação de Primeiras estórias: “O centro da existência é um sumidouro. Pode-se apenas circundá-lo, ganhá-lo pelos flancos, na espreita, de corpo pronto para outra emboscada. O Pai resolveu colocar-se no centro, na raiz proibida do humano. [...] // O Pai ancorara na margem inconcebível em termos de razão humana”.

4 Difícil aqui não lembrar o belo poema "Boi morto", de Manuel Bandeira, publicado em Opus 10, onde encontramos a mesma associação entre a imagem do movimento turbilhonante das águas e a sonoridade obtida pela aliteração do $/ \mathrm{r} /$ e pela assonância do /o/: "Como em turvas águas de enchente, / Me sinto a meio submergido / Entre destroços do presente / Dividido, subdividido, / Onde rola, enorme, o boi morto // Boi morto, boi morto, boi morto". Não há também como não recordar o célebre dito recorrente de Riobaldo: "Viver é muito perigoso...".

5 Num encontro realizado há alguns bons anos pelo professor Alcides Villaça com seus orientandos para a discussão do conto de Rosa, o orientador já havia chamado a atenção para esse distanciamento sugerido na própria formulação da frase pela mãe do protagonista. É bem provável que outros aspectos do conto referidos neste ensaio tenham como origem esse profícuo debate.

6 Aqui, Rosa aproveita-se da ambiguidade provocada pela homonímia entre as formas verbais dos verbos ser e $i r$, na terceira pessoa do singular do pretérito perfeito: "Sou que não foi" ao encontro do pai ou simplesmente "Sou o que não foi", isto é, o que não "existiu", o que de fato não "viveu".

7 "Essa terceira margem tenta escapar a uma lógica binária a que a mente humana parece condenada” (Galvão, 2008, p.43).

8 Se a expressão em português - o terceiro não excluído - encontra no título do conto de Rosa uma correspondência imediata no emprego do número ordinal, o que nos dois casos parece enfatizar que se trata de uma nova possibilidade, uma nova via ou um novo caminho que se abre para além das duas possibilidades normalmente consideradas num sistema binário, a expressão original de Wallerstein, em inglês, "the unexcluded middle" aproxima-se da imagem do leito do rio do conto de Rosa, que corre entre as duas margens, o que realça o fato de que essa nova possibilidade participa de algum modo das duas possibilidades usuais.

9 Disponível em: <http://hlchang.tumblr.com/post/49572945254/paulo-leminski-o-ideograma-kawa-rio-em>. Acesso em: 11 ago. 2014.

\section{Referências}

COUTINHO, E. de F. Guimarães Rosa. Rio de Janeiro: Civilização Brasileira, 1983.

GALVÃO, W. N. Do lado de cá. In: . Minima mímica: ensaios sobre Guimarães Rosa. São Paulo: Cia. das Letras, 2008. p.41-6.

HOLANDA, S. B. de. Perspectivas. In: O espirito e a letra: estudos de crítica literária I - 1920-1947. Org. Antonio Arnoni Prado. São Paulo: Cia. das Letras, 1996. p.214-8.

HORKHEIMER, M.; ADORNO, T. W. Contradições. In: Dialética do esclarecimento: fragmentos filosóficos. Trad. Guido Antonio de Almeida. Rio de Janeiro: Zahar, 1985. p.221-4. 
LIMA, L. C. O mundo em perspectiva: João Guimarães Rosa. In: COUTINHO, E. de F. Guimarães Rosa. Rio de Janeiro: Civilização Brasileira, 1983. p.500-13.

ROSA, J. G. Primeiras estórias. 26.ed. Rio de Janeiro: Nova Fronteira, 1993.

WALLERSTEIN, I. O tempo, a duração e o terceiro não excluído: reflexões sobre Braudel e Prigogine. Trad. Sonia Lacerda. In: LOPES, M. A. (Org.) Fernand Braudel: tempo e história. Rio de Janeiro: Editora FGV, 2003. p.71-80.

RESUMO - O ensaio procura mostrar como o título e o enredo de "A terceira margem do rio", o célebre conto de Primeiras estórias, de João Guimarães Rosa, podem ser aproximados da noção de "terceiro não excluído", tal como proposta por Immanuel Wallerstein, em artigo sobre Fernand Braudel e Ilya Prigogine. Nessa perspectiva, o conto apontaria para a existência - na vida como na literatura - de um terceiro caminho, que não exclui mas participa dos dois caminhos usualmente apresentados como mutuamente excludentes pelo pensamento binário - tão difícil de ser superado, como o demonstra um fragmento de Adorno e Horkheimer.

PALAVRAS-CHAVE: João Guimarães Rosa, Primeiras estórias, Conto, O terceiro não excluído.

ABSTRACT - This essay seeks to show how the title and the plot of "A terceira margem do rio" [The third bank of the river], the acclaimed short story from the book Primeiras estórias, by João Guimarães Rosa, relate to the notion of "the unexcluded middle," as discussed by Immanuel Wallerstein in an article on Fernand Braudel and Ilya Prigogine. In this perspective, the short story emphasizes the possibility of a third way that does not exclude, and indeed encompass, the two paths that are often presented as mutually exclusive by the binary thinking - a system that is very difficult to surmount, as a fragment by Adorno and Horkheimer shows.

KErWORDS: João Guimarães Rosa, Primeiras estórias, Short story, The unexcluded middle.

André Luis Rodrigues é professor de Literatura Brasileira do Departamento de Letras Clássicas e Vernáculas da Faculdade de Filosofia, Letras e Ciências Humanas da USP e autor de Ritos da paixão em Lavoura arcaica.

@ - andreluisrod@hotmail.com

Recebido em 12.8.2014 e aceito em 9.12.2014.

${ }^{\text {I }}$ Faculdade de Filosofia, Letras e Ciências Humanas, Universidade de São Paulo. São Paulo/São Paulo, Brasil. 
